\title{
Resonant Experience in Emergent Events of Analysis
}

\author{
Line Revsbæk \\ Aalborg University, Department of Political Science, Fibigerstræde 3, 9220 Aalborg Øst: Denmark \\ (revsbaek@learning.aau.dk)
}

\begin{abstract}
HEORY, and the traditions of thought available and known to us, give shape to what we are able to notice of our field of inquiry, and so also of our practice of research. Building on G. H. Mead's Philosophy of the Present (1932), this paper draws attention to 'emergent events' of analysis when working abductively with interview data in a process of re-experiencing interview material through listening to audio recordings of qualitative research interviews. The paper presents an emergent event of analysis in which the theoretical argument of (the researcher's) Self as a process of becoming in responsive relating to (case study) others is made generative as a dynamic in and of case study analysis. Using a case of being a newcomer (to research communities) researching newcomer innovation (of others), 'resonant experience' is illustrated as a heuristic in interview analysis to simultaneously deconstruct/reconstruct dichotomous concept categories known to organize the research literature in a field.
\end{abstract}

KEYWORDS: analysis, interview analysis, process ontology, resonant experience, emergent event, G. H. Mead.

It is true of all our experience that it is the response that interprets to us what comes to us in the stimulus. (Mead, 1934: 114)

\section{Process Ontology in Research Methodology}

An 'ontological realm of inquiry' (Shotter, 2015) has recently been heralded by the introduction of process philosophy to organization studies (see for example Helin et al., 2014; Langley \& Tsoukas, 2017) and by 'thinking with theory' in qualitative inquiry (Jackson \& Mazzei, 2017; see also Jackson \& Mazzei, 2013; St. Pierre, 2011). The turn to ontology in methodology that a process disposition suggests is often referred to by the idiom of inquiring from within. Thus, in 'strong' process-ontological views on methodology, the researcher's position towards the researched is understood in terms of 'a participant from within' the flow of experience, rather than of 'an outside observer' of it (Fachin \& Langley, 2017). Elaborating on this paradigm shift concerning assumed researcher positionality, organization scholar John Shotter, a significant figure in exploring the implications of process ontology for the understanding of methodology in process organization studies, states: 'all our usual representational methods - that place us over against the reality we are trying to understand - are all excluded by our primary assumption of being ourselves participant parts of a larger indivisible' process (Shotter, 2010: 75). Shotter argues that adopting a process orientation in our practice of research confronts us 'with the task of evolving new ways of relating ourselves (bodily, i.e., sensitively and emotionally) to the others and othernesses around us' (Shotter, 2010: 74), and, consequently, such different relating will affect the 'what' of ourselves, and that of others, made noticeable in a research encounter. In opposition to the 'about-ness' knowledge (Shotter, 2006) characteristic of Cartesian knowledge claims on things 'already there' independent of a researcher subject, and of research practices identifying them, the aspiration among process scholars to develop understanding from within evolving phenomena is sometimes referred to by a signifier of 'with-ness thinking' (ibid.).

\section{The Becoming of Self As A Dynamic in Analysis}

Arguments characteristic of the emergent paradigm of post-qualitative research have, 
from similar process-relational ontology, troubled assumptions about the 'always-already subject' researcher dealing with 'alwaysalready object'-ified and fixed data which are inherent in conventional qualitative methodology (Jackson \& Mazzei, 2013; St. Pierre, 2011). Working from postmodern and poststructuralist challenges to humanist assumptions about the researcher subject 'over against' a reality to be explored, post-qualitative researchers emphasize that 'data' to the process of analysis is not only that which is textualized and fixed prior to analysis, but also aspects of experience transgressive to different modalities (St. Pierre, 1997), different participants, and voices of informants and theorists, and as such collected and re-collected during the process of analysis rather than exclusively prior to it (St. Pierre, 2011). The debate among post-qualitative researchers drawing on Derrida and on Deleuze and Guattari has drawn attention to the circumstance of working with and as 'unstable subjects' in research: "If the "I" of the participant is always becoming in the process of telling, so too the "I" of the researcher is always becoming in the process of researching, listening, and writing' (Jackson \& Mazzei, 2013: 266). Illustrating the performative stance of such process ontology in methodology, Bronwyn Davies suggests engaging in qualitative inquiry 'to access that which is becoming true, ontologically and epistemologically, in the moment of the [research] encounter' (Davies, 2016: 75). Drawing on Barad, Davies proposes focusing 'on the ongoing intra-active processes through which selves come into being and go on coming into being in complex emergent relationality' (Davies, 2016: 75). Similarly, Shotter (2010) points out that we as investigators 'ourselves can be radically changed in such encounters' (ibid.: 15). A different kind of 'embodied sensings or feelings' (ibid.: 4) and 'spontaneously responsive understanding' (ibid: 13), Shotter suggests, becomes available and noticeable to us when we relate in 'an inner fashion to the becoming of things (rather than observing them from the outside)' (ibid.: 15).

This paper explores the contribution of Mead's notion of 'the emergent event' for understanding researcher and participant becoming in the process of analysing. The paper presents an emergent event of interview analysis in which the theoretical argument of (the researcher's) Self as a process of becoming in the responsive relating to (case study) others is made generative in the interview analysis, thus serving as a dynamic in and of analysis. Resonant experience is presented as the shaping of lived experience which takes place as a case study participant's expressed experience is perceived to challenge established concept categories, thus evoking a reorganization of researcher's own experience to the resonance it holds to that expressed by the case study other. Drawing on Mead's concept of the emergent event (Mead, 1932), the paper accounts in detail for the 'when' of resonant experience in interview analysis.

\section{Taking The Attitude of Process Theory}

Elaborating on the role of theory, and of process philosophy to stances in methodology, Spivak's account (2014) of the reading of theory may offer perspective. Spivak explains her own and her students' practice as one of reading the theory 'as if we were writing it' (Spivak, 2014: 77). By entering 'the protocol of the other person's theory, [and] its private grammar, so that the theory transforms you' (Spivak, 2014: 77), one 'internalizes' the theory to the point of it becoming 'part of our mental furniture' (ibid.). From Spivak, we understand theory to come in 'as a reflex' (ibid.), that is, as part of our researcher sensitivity evoked in research encounters, giving shape to what we are able to notice both of our field of inquiry, and of our practices of research.

»Taking the attitude (Mead, 1934) of a process philosophy/philosopher as that of our own towards the doings and dealings of our research is one such way of relating differently to materials and participants in our practice of research, as advocated by Shotter. By emphasizing the 'I-me' dialectic in G.H. Mead's theory of becoming a Self in a collective (Mead, 1934), we understand such relating (differently) as taking place, responsively, in spontaneous enactments of a research practice, as the researcher in a specific situation responds to everything at hand in her doing. All the methodological theory that we as researchers are familiar with, and are able to witness enacted in practised research 
methodologies, becomes, in Meadian terminology, our methodological 'me' (ibid.) to which we respond in our own situated practising of research by the spontaneity of the Meadian 'I'. Taking a 'strong' process-ontological stance in methodology is, in a Meadian vocabulary, understood as 'taking the attitude' of the process philosophy in the doing of the research.

\section{Situating Resonant Experience in Emer- gent Events: The »When « of Resonant Ex- perience}

\begin{abstract}
It is idle, at least for the purposes of experience, to have recourse to a 'real' past [...] for that past must be set over against a present within which the emergent appears, and the past which must then be looked at from the standpoint of the emergent, becomes a different past [...] It is the 'what it was' that changes. (Mead, 1932: 36-37)
\end{abstract}

In his paradoxical notion of time, argued as one of the most radical in social science (Fine \& Flaherty, 2001), Mead (1932) seats ontological reality in the living present, in here-andnow present situations. 'The world is a world of events', he argues (1932: 35), explaining 'a present $[\ldots]$ is not a piece cut out anywhere [...] Its chief reference is to the emergent event' (Mead, 1932: 52). To Mead, the 'emergent event' is key in understanding time and temporality, and it is characterized by the occurrence of novelty, that is, of something not previously present in the processes that led up to it (ibid.). Hence, Mead considers time not primarily as a chronologically unfolding series of occurrences (although he acknowledges the irrevocability of time, stating 'that which has happened is gone beyond recall', Mead, 1932: 37). Much more, Mead's Philosophy of the Present (1932) is about understanding the structure of time in the living present, which means the organizing of past and future in the occasion of the emergent event of a living present. It is this structuring of time, in emergent events of analysis, that is described as a dynamic of analysis in this paper. According to Mead, past and future, themselves nowhere else to be found but in the present, are understood as 'epistemological resources' for continuous acting, partaking and understanding in the living present (Simpson, 2014).

Related to pragmatism's concept of abductive reasoning (Pierce, 1978), constituting the relationship between situation and inquiry (Brinkmann, 2014), Mead states: 'data are such emergent events as fail to fit into the accepted structure of relations, and become nodal points from which a new structure of relations arises' (Mead 1932: 116). Characteristic of the emergent event is that it "marks out and in a sense selects what has made its peculiarity possible. It creates with its uniqueness a past and a future' (ibid: 52) and reorganizes past (experience) and (anticipations of) future in the living present. The peculiarity of (such 'data' as) emergent events is thus generative of a reordering of (past) experience. It is this reordering that drives the analysis through resonant experience argued in this paper.

Listening to interview audio recordings is an occasion for re-experiencing the interview material, and this experience is different from that of reading interview transcripts, in that the listening is rich in 'sense data' such as intonations, rhythm, timing and our own recalled sense of being present in the interview as interviewer (Revsbæk \& Tanggaard, 2015). Daza and Gershon (2015) have recently described methodologies of sound-in contrast to that of visuals-as a means to consider 'complex interrelations', 'echoes across time and contexts', 'the breaking down of barriers between siloed fields' and 'an opening up of relationships within and between ecologies' (Daza \& Gershon, 2015). Responses evoked in us when listening to an interview recording answer to such broader contextuality.

As is illustrated in a later section, the peculiarity and paradox of the expressed experience of a case study other, may, in relation to existing knowledge structures in a field, constitute a deconstruction and a 'breakdown-inunderstanding' (Alvesson \& Kärreman, 2011), thus eliciting recollections of the researcher's own experience brought, then, to relate to that expressed by the case study other by the deconstruction it poses to established concept categories. 


\section{Case}

The following originates from a case study on organizational socialization and newcomer innovation in a large industrial company in Denmark (Revsbæk, 2014). ${ }^{1}$ An interview design inclusive of organizational newcomers, their veteran co-workers and hiring managers portrays 'being insider' and 'being outsider' as situational attributes-at times inhabited by organizational veterans, at times by newcomers-more so than appearing as fixed participant categories reflecting seniority of employment.

\section{Listening to the Interview Recording: Be- coming The One to Understand The Other}

A veteran co-worker to a newly employed engineer project manager in the company supply chain management department talks extensively in the interview recording about an institutionalized practice of 'team training' and related principles of 'process leadership'. Apparently, the practice of doing a monthly team training workshop conducted by company external consultants was introduced by the business unit president a few years back. The business unit president sponsors the programme of team training, and the training is meant for team members to get to know each other better and gain an understanding of the various individual ways of working, thus fostering wellbeing in work and team collaborations.

As the interviewer of the veteran coworker, it turns out that I am not being sensitive to the situation that he and I share early in the interview. And I am reminded of this as I listen to the interview recording. Acting in the interview like an elephant in a china shop, I let an ironic remark on the practice of team training slip spontaneously from my tongue. In case study interviews prior to this one, I have heard other case study participants talk about this practice of team training in a reasonably loyal, but also disengaged and somewhat ironic manner, implying to me a low degree of ownership with regard to this practice. I then accidentally assume that this veteran co-worker will express the same ironic attitude towards the practice, but I am wrong. He appreciates the team training and speaks extensively about it. His preoccupation with the training con- trasts with his new manager's and newcomer colleague's disengagement towards it.

I dwell on the question of why this veteran co-worker speaks with a confidently committed voice with regard to some aspects of the work, those to do with 'team training' and 'process leadership', whereas he speaks with an inferior voice with regard to those aspects of the work to do with 'engineering' and 'engineerdriven project management' (advocated by his new manager as a key lever for improving their department status in the company). The veteran co-worker states in a disparaging and inferior voice that he feels 'uncertain about what is going to happen [in the light of announced future layoffs], because-this is just my own self-image-but, I am an economist by education and the others are engineers'. I am reminded of Gallagher and Sias's study (2009) on 'uncertainty management' as relevant not only to organizational newcomers, but also to veterans concerned with their job security in times of managerial rehiring-a study in stark contrast to most studies on organizational socialization focused on the uncertainty experienced by newcomers and the positioning of organizational veterans exclusively as 'socialization agents' to the newcomers (Feldman, 2012).

As researcher at the time, I was seeking to convey (and understand) this story of the veteran co-worker who speaks with a marginalized voice concerning some aspects of the work, yet a superior and almost corrective voice with regard to other aspects of the work. Listening to the recorded interview, getting caught up in this paradox of 'inferior yet superior', an experience of my own springs to mind as if explaining the ambiguity in the story of the veteran coworker. I start writing an autobiographical narrative on this resonant experience to see what insights into the veteran co-worker's story can be created by doing so.

\section{Researcher's Autobiographical Narrative: Being The Possibly Excluded}

In a seminar in the research community that I was visiting, the doctoral students and faculty members of the community were discussing the recent withdrawal/exclusion of a student from the programme. The head of faculty said that the withdrawing student had been really strug- 
gling with the work. In an email responding to my work, prior to the seminar, the same faculty member had used the same choice of words on my work: 'it seems you are struggling', he wrote.

As any researcher knows, the word 'struggle' is often a positive term describing researcher dedication, commitment and intense engagement with the materials at hand. Thus, 'struggle' might be a quality stamp on my work if I was said to be 'struggling' in this sense. But it didn't quite 'sound' like that when I read the email, though I can't exactly say why. Perhaps it was the way he stated his critique of my writing rather directly before concluding that I seemed to be 'struggling'. Or perhaps I was reading in impressions from prior face-to-face meetings contributing to this sense of not exactly being complimented on researcher virtues with this remark.

Situated in the research community meeting, with its members discussing the departure of this recent community member by reference to his 'struggles', it seemed to me that a criterion of exclusion was possibly emerging. And it occurred to me as such because I was sensing that I too might fall short in relation to this criterion of 'a struggle' or, rather 'too much of a struggle'. I was becoming the possibly excluded. The community members were now more explicitly discussing inclusion-exclusion criteria: a commitment to reading theory, familiarizing oneself with the theoretical heritage of the community, meeting deadlines, engaging in the frequent peer-review process of fellow students' work and paying attention to the process of personal development emergent in the research process. Almost as if settling and agreeing on such criteria might secure the sense of security of the involved. I felt a need to speak up. I was uncomfortable, falling short of exclusion criteria sensed yet not explicated.

The courage to speak came with the thought that I might not be the only one feeling like this. And since I was only visiting the community, I might as well attempt to find the voice I did not dare to use. 'I guess exclusion criteria emerge', I started out, expecting this opening discourse to be in resonance with the theoretical stance shared among community members, 'in what we say, and how it is taken up by others; I think
I might be struggling'. I had identified myself with the member who had just left/been asked to leave. I had to mobilize my courage in order to convey the thought and make visible the vulnerability I felt. I remember looking at the faculty member who had, in conversations prior to this one, been most supportive in my attempts at putting words to the interactions between us, and implicitly addressing him as I closed my statement. I did so, describing how I was thinking we might be creating a criterion of exclusion related to 'struggling' from the way we were making sense of the departure of the recent student member, further explaining that I was guessing this from my own sense of possibly being excluded or losing community status with reference to this criterion, since I was definitely struggling, and had also been described as doing so by a faculty member. I closed my statement by saying 'at least I took up voice', hoping it would be acknowledged. Anticipating that it would, from the familiarity with the community values I was starting to get a sense of.

Almost instinctively and certainly unaware of it at the time, I was pleading for another cult value of the community, one in which I would be included. 'Voicing'. And I was recognized. By the supportive faculty member. He nodded. That was enough. 'Struggling' did not remain a criterion of exclusion. It equated to one at some stage in the conversation, at least in my perception. Then, the conversation changed, and so did the criterion of exclusion. I was no longer the possibly excluded. I no longer sensed the exclusion criteria, but I guess they were still there. Perhaps to do with 'voicing'. But they were not calling me out. At least not currently.

\section{Resonant Experience}

Following Mead (1932), the lived experience of a listening researcher (like that of a case study participant) is not shaped in a fixed manner prior to their encounter. On the occasion of listening to an interview recording, the researcher's lived experience is not even shaped prior to the post-interview listening. It finds shape in the listening, from and as the resonance between the expressed experience of the case study participant and researcher's own.

The incident described in the autobiograph- 
ical narrative took place in July 2013. It was written in November that year, coming back to me in memory in response to listening to the case study participant's account of his experience in the audio-recorded interview originally conducted in February 2011 and made an object of analysis in November 2013.

The case illustrates making the temporal process of experience work as a dynamic in and of analysis, allowing the novelty of the expressed experience of the case study other to evoke resonant experience of researcher's own. Recalling my own experience as one of becoming 'the possibly excluded', enabled considering the veteran co-worker's story and his inferior voice concerning some aspects of the work, yet superior voice concerning other aspects of the work, as a case of the veteran co-worker, in the face of perceived possible exclusion, making a plea for another community cult value: one that would allow him to stay included, that of 'process leadership' and 'team training'. The shaping of experience to the resonance between that expressed by the case study other and the evoked of researcher's own in an emergent event of analysis takes place beyond vocabulary and theory, and it does so as the expressed experience of the other becomes 'Meadian data' in the sense of an 'emergent event' failing to fit into the structure of concept relations that otherwise organize the field of research. With a deconstructive effect, the expressed experience by the case study other becomes a nodal point from which a new structure, a reorganization of past experience (including researcher's own), takes place. Dwelling 'in the moment of the pause before difference emerges' (Davies, 2016: 74), the expressed experience of the other takes shape in this emergent event of analysis, at first, in and by the resonance it holds to that elicited by researcher's own. Eventually, this shaping does not become $a$ particular identified shape without theory and vocabulary also coming in 'as a reflex' (cf. Spivak, 2014). In the reported case study on organizational newcomers and veterans, theory and the words of complexity theorist Ralph Stacey helped shape the expressed and resonant experience to the reminder that 'values have the effect of including those who adhere to them and excluding those who do not, so establishing collective or "we" identities for all the individuals in both groupings' (Stacey, 2010: 165).

Mead reminds us: 'there may be and beyond doubt is in any present with its own past a vast deal which we do not discover, and yet this which we do or do not discover will take on different meaning and be different in its structure as an event when viewed from some later standpoint (Mead, 1932: 40). Hence, resonant experience of our own, evoked in emergent events of analysis, may be such perhaps previously-notdiscovered aspects of experience which take on new meaning and new structure from the standpoint of grasping those aspects of the expressed experience of a case study other that are ill-captured by, or even in discord with, inherent knowledge categories and structures characteristic of the research field in question. As researchers we may not know prior to the process of analysing what aspects of our own experience could serve as a lever in understanding that expressed by case study others. In my own doctoral study reported above I more so arrived at being the newcomer (to research communities) who was researching newcomer innovations others, than I started out as such.

\section{Generative Reflexivity}

Necessary to any social conceptualization of Self, Mead argues the need for understanding individual experience from a standpoint of society, and describes the scope of social psychology as one of determining 'that which belongs to [the individual's] experience because the individual himself belongs to a social structure' (Mead, 1934: 1). As process sociologist Norbert Elias reminds us about being social scientists, we are ourselves part of the (societal) figurational patterns of participation that we investigate (Elias, 1956). Hence, deconstruction of the knowledge structure (in a field of research) assumed to represent societal or general social/organizational figurations of participation stipulates a reorganization of concept structures implicating identity categories also significant to the organization of the researcher's own lived experience. By this 'impossibility of standing outside experience' (cf. Stacey, 2012), attention is brought to researcher reflexivity and the role of researcher's reflexivity in case study analyses. 
From the case of being a newcomer, researching the newcomer innovation of others, what is suggested here is for the researcher's own history of experience to feature as a kind of 'field-shaped' sensitivity (Müller, 2016: 707), constitutive of the 'what' that a researcher is able to make hearable, noticeable and thus understandable of that which is encountered. Mead will have us recognize of the relationship between an organism and its environment, that 'the nature of environment answers to the habits and selective attitudes of organisms, and the qualities that belong to the objects of the environment can only be expressed in terms of sensitivities of these organisms' (Mead, 1932: 53). Thus, situating research in emergent events of analysis draws attention to what a subject matter is able to become in the encounter of specific participants engaged in (case study) inquiries. From the simultaneity of 'the two' in the emergent event of analysis, the 'who' of the identifier and the 'that' of the identified constitute simultaneously and in resonance. It is not only a 'who' of the identifier that reflects into and influences the identification of the 'that' of the encountered (as is characteristic of a Cartesian distinction between subject and object as antecedent entities). Instead, the identified 'that' (of the encountered) reflects into and selects out the 'who' of the identifier identifying this. Such a dynamic of emergence in responsive interaction is, in this paper, understood from Mead's conceptualization of the emergent event. Researcher reflexivity thus becomes less about relativizing knowledge claims and self-critical subtracting from results, and more about a generative settling of identification of what we take to be characteristic of the other from the resonance it holds to ourselves, recalling this paper's introductory quote: 'it is the response that interprets to us what comes to us in the stimulus' (Mead, 1934: 114). Hence, we may learn about what we encounter from what we become in encountering it.

Implications for Future Research: Iterative Analysis and Responsive Reorganizing of Knowledge and Acknowledged Experience Paying attention to resonant experience in emergent events of analysis would most often, in my work, be one aspect of a broader strategy of analysis to explore 'what', of case study experiences, is serving the emergence of new (concept and identity) categories grasping a current circumstance and quality of participation in the field under investigation.

Davies writes on listening that 'allowing the resonance of the other to register in one's body involves opening oneself to an ongoing process of Deleuzian differenciation, to become other, to a process of evolution that takes one beyond the already known' (Davies, 2011: 1). In the case of 'the possibly excluded', such registering of the other in oneself is argued situated in emergent events of expressed experience of a case study other posing a challenge to existing knowledge structures (in which the researcher is inherently a participant). 'Our whole being', it is argued by French philosopher of the phenomenology of listening Jean-Luc Nancy, 'is involved in listening, just as it is involved in interpreting what it hears' (Nancy \& Mandell, 2007: $\mathrm{xx})$.

My argument is not one of claiming the expressed experience of the case study other to be the same as mine, or that identifying mine would be representational of that of the other. The aim of working responsively in analysis, as here suggested, in drawing attention towards resonant experience in emergent events of analysis, is not one of representation. Rather, it concerns iterating the consequence of a break posed by expressed experience of case study others to the conceptual organizing of experience: Which account and experience becomes possible to be with when the expressed experience of another, breaking away from dominant structures of categorization, is made a nodal point for the emergence of a new conceptual structuring? Questions like this are analytic levers when analysing and developing understanding through resonant experience.

The responsive and iterative way of analysis might be extended by iterating the emancipatory effect through other parts of the case study material, and through the literature, to see what pattern of association and what concept figurations emerge when working abductively and iteratively like that in analysis. Analysis, then, becomes a process of responding, by the organizing and reorganizing of material, experience and knowledge structures, to the epistemologi- 
cal emancipation performed in emergent events of the analysis with expressed experience posing a challenge to existing knowledge structures. Iterating an emergent event of analysis, captured by resonance in experience, across a vast variety of case study materials, research literature and future occurrences produces, over time, new figurations in and of the case study material.

\section{Concluding Remarks}

Resonant experience has in this paper been suggested as a process-ontological heuristic in case study interview analysis. As illustrated, resonant experience may serve to 'capture' the abductive element of the expressed experience of a case study participant, giving this element its first iterative shape by the resonance it holds to the evoked experience of the (listening) researcher.

Social categories organizing a field of research may over time evolve into simplistic dichotomies no longer helpful in grasping current circumstance in social and organizational life. In times of increased alienation with regard to such acknowledged and reified identity positions, iterating resonant experience from emergent events of analysis may serve as an analytic heuristic to arrive at new/altered social categories both enabling and requiring a reorganization of current concept structures.

Drawing on G. H. Mead's Philosophy of the Present (1932), the paper has illustrated the process of becoming a Self in continuous processes of relating as a possible dynamic in and of analysis. G. H. Mead's concept of 'the emergent event' has been explored in terms of the deconstructing/reconstructing dynamic of working with resonant experience in interview analysis. The paper is a contribution to the present endeavours of process scholars exploring what process ontology in research methodology entails for the enactment of research practice.

\section{Endnotes}

1. The case is a revised version of one published in Revsbæk, 2014, and presented at the Annual Symposium on Process Organizational Studies (PROS), June 2015, Kos.

\section{References}

Alvesson, M. \& Kärreman, D. (2011). Qualitative Research and Theory Development. Mystery as Method. London: Sage.
Brinkmann, S. (2014). Doing without data. Qualitative Inquiry, vol. 20(6), pp. 720-725. doi: $10.1177 / 1077800414530254$

Davies, B. (2011). Listening: a radical pedagogy. Challenging gender: Normalization and beyond, 1-17. Working paper: https://www.google.co. $\mathrm{uk} / \mathrm{url}$ ? sa $=\mathrm{t} \& \mathrm{rct}=\mathrm{j} \& \mathrm{q}=\& \mathrm{esrc}=\mathrm{s} \&$ source $=\mathrm{web} \&$ $\mathrm{cd}=3 \& \mathrm{cad}=$ rja\&uact $=8 \&$ ved $=0$ ahUKEwja0Jb26jaAhWKJsAKHXZpC-AQFgg2MAI\&url= https\%3A\%2F\%2Fis.muni.cz\%2Fel\%2F1423\% 2Fpodzim2009\%2Fsoc932\%2Fum\%2F8834758\% 2FListening-_a_radical_pedagogy_11_08_09.pdf\& usg=AOvVaw1h_rNGmHcQ_iK9eROTrfTU.

Davies, B. (2016). Emergent Listening. Qualitative Inquiry Through a Critical Lens, 73.

Daza, S., \& Gershon, W. S. (2015). Beyond Ocular Inquiry: Sound, Silence, and Sonification. Qualitative Inquiry, 1077800414566692.

Elias, N. (1956). Problems of involvement and detachment. The British Journal of Sociology, 7(3), 226-252.

Fachin, F. F. \& Langley, A. (2017). Researching Organizational Concepts Processually: The Case of Identity. In Cassell C., Cunliffe A. \& Grandy G. (Eds.) The Sage Handbook of Qualitative Business and Management Research Methods: History and Traditions, 308. Thousand Oaks, CA: Sage.

Feldman, D. C. (2012). The impact of socializing newcomers on insiders. In Wanberg, C. (ed.), The Oxford handbook of organizational socialization, 215-229.

Flaherty, M., \& Fine, G. A. (2001). Present, past, and future: Conjugating George Herbert Mead's perspective on time. Time \& Society, 10, 147-161.

Gallagher, E. B., \& Sias, P. M. (2009). The new employee as a source of uncertainty: Veteran employee information seeking about new hires. Western Journal of Communication, 73(1), 23-46.

Helin, J., Hernes, T., Hjorth, D., \& Holt, R. (2014). Process is how process does. In J. Helin, T. Hernes, D. Hjorth, \& R. Holt (Eds), The Oxford Handbook of Process Philosophy and Organization Studies (pp. 1-16). Oxford, UK: Oxford University Press.

Jackson, A. Y., \& Mazzei, L. A. (2013). Plugging One Text into Another: Thinking with Theory in Qualitative Research. Qualitative Inquiry, 19(4), 261-271.

Jackson, A. Y., \& Mazzei, L. A. (2017). Thinking with theory: A new analytic for qualitative inquiry. In N. K. Denzin \& Y. S. Lincoln (Eds.), The SAGE handbook of qualitative research, 5th ed., (pp. 717-737). Thousand Oaks, CA: SAGE.

Langley, A., \& Tsoukas, H. (2017). Introduction: Process thinking, process theorizing and process researching. The SAGE Handbook of Process Organizational Studies, 1-25.

Mead, G. H. (1932). The Philosophy of the Present (this edition 2002). Amherst, New York: Prometheus Books. (Originally published: Chicago: Open Court Pub). 
Mead, G. H. (1934). Mind, self, and society: From the standpoint of a social behaviorist (C. W. Morris, Ed.). Chicago, IL: The University of Chicago Press.

Nancy, J. L., \& Mandell, C. (2007). Listening. Fordham Univ Press.

Pierce, C.S. (1978). Pragmatism and abduction. In C. Hartshorne \& P. Weiss (Eds), Collected Papers vol. V (pp. 180-212). Cambridge, MA: Harvard University Press.

Revsbæk, L. (2014). Adjusting to the Emergent. A process theory perspective on organizational socialization and newcomer innovation. (Doctoral thesis). Aalborg, DK: Aalborg University Press.

Revsbaek, L. \& Tanggaard, L. (2015). Analyzing in the Present. Qualitative Inquiry, vol. 21(4), 376-387.

Shotter, J. (2010). Adopting a process orientation... in practice: Chiasmic relations, language, and embodiment in a living world. In Hernes, T. \& Maitlis, S. (Eds.), Process, sensemaking, and organizing (Vol. 1), Oxford, UK: Oxford University Press, pp. 70-101.

Shotter, J. (2015). On "relational things": A new realm of inquiry-pre-understandings and performative understandings of people's meanings. The emergence of novelty in organizations, 56-79.

Simpson, B. (2014). George Herbert Mead (1863-1931). In J. Helin, T. Hernes, D. Hjorth, \& R. Holt (Eds.), The Oxford Handbook of Process Philosophy and Organization Studies (pp. 272-286). Oxford, UK: Oxford University Press.

St. Pierre, E. A. (1997). Methodology in the fold and the irruption of transgressive data. International Journal of Qualitative Studies in Education, 10(2), 175-189.

St. Pierre, E.A. (2011). Post qualitative research: The critique and the coming after. In N.K. Denzin \& Y.S. Lincoln (Eds), The SAGE Handbook of Qualitative Research, 4th ed. (pp. 611-625). Thousand Oaks, CA: Sage.

Stacey, R.D. (2010). Complexity and Organizational Reality. Uncertainty and the Need to Rethink Management after the Collapse of Investment Capitalism, 2nd Ed. Oxon, UK: Routledge.
Stacey, R. (2012). Tools and Techniques of Leadership and Management. Meeting the Challenge of Complexity. Oxon, UK: Routledge.

\section{About the Author}

Line Revsbæk $\mathrm{PhD}$, MSc in psychology, is an associate professor at the Department of Learning and Philosophy, Aalborg University, Aalborg, Denmark. She has held positions at the University of Southern Denmark and was a visiting student at the Complexity and Management Group, Hertfordshire University, UK, during her doctoral studies. Her research focuses on organizational socialization, employee induction and the social dynamics of collaboration and organizational life. She works from process ontology, pragmatism and complexity theory perspectives to develop research practice and methodology in terms of complex responsive processes. She has been engaged in participatory action research on employee induction/onboarding in academic, state government and private sector organizations, and is currently (together with Lærke Gelineck Berg and Søren Willert) researching collaborative reflexive writing as a method of leadership development in a Danish municipality. Recent publications include Revsbæk, L. (2014), Adjusting to the Emergent. A process theory perspective on organizational socialization and newcomer innovation, Aalborg University Press, Aalborg; Revsbæk, L. \& Tanggaard, L. (2015), Analyzing in the Present, Qualitative Inquiry, vol. 21(4), 376-387; Mosleh, W. S. \& Revsbæk, L. (2017), Fieldworking relational complexity: Entangled in managerial dynamics, conference paper, EGOS, July 6th-8th, Copenhagen; Ylirisko, S., Revsbæk, L. \& Buur, J., Resourcing experience in co-design, Conference proceedings from DTRS11 (2017); Revsbæk, L. (2016), Making methodology a matter of process ontology, Organisation und Methode. Beiträge der Kommision Organisationspädagogik, Springer VS (eds. Göhlich, M., Weber, S. M., Schröer, A. and Schemmann, M., 2016). 